\title{
Inland ENC: Perspectivas para a Cartografia Fluvial no Brasil
}

\author{
Inland ENC: Perspectives for Fluvial Cartography in Brazil
}

F. Mandarino ${ }^{1,2}$, A. Ayres Neto', V.H.M. Folly ${ }^{3}$

Recebido em abril de 2018.

Aprovado em novembro de 2018.

\begin{abstract}
RESUMO
Tradicionalmente, a produção das cartas náuticas oficiais dos rios brasileiros tem sido desenvolvida a partir de dados coletados em levantamentos hidrográficos usando ecobatímetros monofeixe. Nos últimos anos, a Marinha do Brasil tem conduzido levantamentos multifeixes, primeiramente no Rio Amazonas e recentemente no Rio Paraguai. Enquanto isso, novas especificações para produtos cartográficos têm sido desenvolvidas mundialmente. No âmbito das cartas náuticas marítimas, as cartas em papel vêm sendo substituídas pelas cartas náuticas eletrônicas (ENC), dados vetoriais que compreendem as feições e informações importantes para a navegação. No que diz respeito às cartas náuticas de rio, seguindo a mesma tendência, outra especificação de produto foi criada: a Inland $E N C$, semelhante à ENC marítima, mas adaptada para o ambiente fluvial. Este artigo tem como objetivo comparar uma Inland ENC derivada de um levantamento monofeixe, usando as técnicas cartográficas da abordagem tradicional e uma outra Inland ENC, produzida a partir dos dados coletados com equipamentos multifeixes no Rio Paraguai, escolhido como área de estudo para as primeiras Inland ENC brasileiras. É a primeira vez que esse processo foi aplicado para produzir cartas do Rio Paraguai a partir de dados hidrográficos coletados pela Marinha do Brasil. Os resultados podem ser utilizados para o estabelecimento de um novo produto para a cartografia náutica oficial do Rio Paraguai.
\end{abstract}

PALAVRAS-CHAVE: Cartografia Náutica. Cartografia Fluvial. Inland ENC.

\begin{abstract}
Traditionally official cartographic production for Brazilian rivers have been elaborated using hydrographic data mainly collected by singlebeam echosounders. In recent years, Brazilian Navy has conducted multibeam echosounders surveys, firstly for Amazonas River and later for Paraguay River. Meanwhile, new cartographic products specifications have been
\end{abstract}

${ }^{1}$ Diretoria de Hidrografia e Navegação, Brasil E-mail: flavia@marinha.mil.br

2Programa de Pós-graduação em Dinâmica dos Oceanos e da Terra, Universidade Federal Fluminense, Brasil. E-mail: aayres@id.uff.br

${ }^{3}$ Centro de Hidrografia da Marinha, Brasil. E-mail: vanessa.hilleshein@marinha.mil.br

Rev. Bras. de Cartografia, vol. 70, Edição Especial "XXVII Congresso Brasileiro de 
developed. In the scope of the maritime nautical charts, paper charts have been replaced by electronic navigational charts (ENC), vector data comprising the features and information relevant to navigation. Regarding the river nautical charts, following same tendency, another product specification was created, the Inland ENC, similar to the maritime ENC, but adapted to the fluvial environment. This paper aims to compare an Inland ENC derived from a singlebeam echosounder survey, using traditional cartographic approach and another Inland ENC produced directly from multibeam echosounder survey data in the Paraguay River, study area for the first Brazilian Inland ENCs. It is the first time this process is adopted for the production of Paraguay River charts out of hydrographic data collected by the Brazilian Navy. The results may support the development of a new product for Paraguay River official nautical cartography.

KEYWORDS: Nautical Cartography. Fluvial Cartography. Inland ENC.

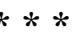

\section{Introdução}

A Marinha do Brasil é responsável pela produção das cartas náuticas brasileiras, tanto para as águas marítimas quanto para as águas interiores. Em relação ao Rio Paraguai, importante via navegável no território nacional, a Marinha do Brasil possui uma organização militar, o Serviço de Sinalização Náutica do Oeste (SSN-6), localizado em Ladário (Mato Grosso do Sul), responsável pelos levantamentos hidrográficos e manutenção da sinalização náutica de $1278 \mathrm{~km}$ do rio, de Cáceres (Mato Grosso) até a foz do Rio Apa (fronteira entre Brasil e Paraguai). Os dados coletados pelos navios e lanchas hidrográficos do SSN-6 são processados e são utilizados para a produção cartográfica, realizada pelo Centro de Hidrografia da Marinha (CHM), organização subordinada a Diretoria de Hidrografia e Navegação (DHN), serviço hidrográfico brasileiro (DHN, 2017).

Tradicionalmente, o CHM produz cartas em papel para o Rio Paraguai a partir de dados coletados pelos meios do SSN-6, equipados com ecobatímetros monofeixe. Geralmente, o levantamento hidrográfico é planejado com base na escala da carta em papel e visa identificar bancos de areia e obstruções para navegação (FRIGO e BLENINGER, 2015). A escala 
da carta estabelece o intervalo entre as linhas de sondagem que o navio percorre coletando dados de profundidade.

A evolução tecnológica, não apenas no âmbito das técnicas e equipamentos para levantamentos hidrográficos, mas no que diz respeito ao equipamento de bordo para navegação, promoveu o desenvolvimento das Cartas Náuticas Eletrônicas (ENC). Estes produtos modernos são utilizados em sistemas como o ECDIS (Electronic Chart Display and Information System), que integram informações de diversos sensores de bordo, como o Sistema de Posicionamento Global (Global Positioning System - GPS), a agulha giroscópica, o radar de navegação, entre outros, de forma a permitir a visualização da embarcação em tempo real sobre a carta náutica e facilitar a tomada de decisão durante a navegação. Embora as cartas em papel ainda estejam em uso, as especificações das ENC são estabelecidas pela Organização Hidrográfica Internacional (OHI) e são usadas no ECDIS a bordo dos navios marítimos em apoio à segurança da navegação. No que diz respeito aos rios e vias navegáveis, os padrões da OHI necessitam ser adaptados para serem adequados às características fluviais típicas, às quais o modelo de dados ENC não é totalmente abrangente.

As cartas náuticas eletrônicas fluviais são denominadas Inland ENC (IENC). A definição oficial de uma Inland ENC é:

\begin{abstract}
"A Inland ENC é o banco de dados, padronizado quanto ao conteúdo, estrutura e formato, para uso com sistemas de exibição e/ou sistemas de informação eletrônica a bordo de navios que transitem em vias navegáveis interiores. Uma IENC é emitida por ou sob a autoridade de uma agência governamental competente e é conforme aos padrões [inicialmente] desenvolvidos pela Organização Hidrográfica Internacional (OHI) e [refinados pelo] Inland ENC Harmonization Group (IEHG). Uma IENC contém todas as informações necessárias para a navegação segura nas vias navegáveis interiores e podem conter informações suplementares àquelas contidas na carta em papel (por exemplo, informações do Roteiro, horários, dados operacionais, etc.) que podem ser considerados necessários para uma navegação segura e para o planejamento da viagem.” (IEHG, 2017).
\end{abstract}

O Inland ENC Harmonization Group (IEHG) é uma organização não governamental, estabelecida em 2003, reconhecida pela OHI como fórum 
especialista responsável pelo estabelecimento das normas harmonizadas para a Inland ENC. A DHN aderiu ao IEHG em 2007 e desde então tem acompanhado as discussões sobre as especificações do produto Inland ENC (MANDARINO, 2015). Em 2016, o SSN-6 realizou seus primeiros levantamentos hidrográficos no Rio Paraguai empregando ecobatímetro multifeixe (SSN-6, 2017). Este artigo traça uma breve comparação entre uma Inland ENC gerada a partir do fluxo de trabalho de produção tradicional, adotado no CHM para as cartas em papel do Rio Paraguai a partir de dados de ecobatímetro monofeixe e uma Inland ENC derivada dos dados de ecobatímetro multifeixe utilizando-se um novo fluxo de trabalho, mais automatizado, que poderá ser adotado pelo CHM para a produção futura de Inland $E N C$ nos rios e hidrovias nacionais.

A região deste estudo corresponde à carta em papel do Rio Paraguai 3442 (Título: Do Posto Agrícola a Cáceres e escala 1:10.000), nas proximidades da cidade de Cáceres (MT), uma das áreas de teste onde o SSN6 realizou seus primeiros levantamentos multifeixe em 2016.

Um levantamento monofeixe foi realizado anteriormente pelo SSN-6 para determinar as áreas a serem levantadas de forma segura com o equipamento ecobatímetro multifeixe. A Figura 1 mostra a edição atual da carta em papel 3442, que será atualizada com os novos dados do levantamento. A linha isobatimétrica de 3 metros define a separação das águas restritas (em azul) do trecho de maior profundidade em branco. 
Figura 1 - Carta em Papel 3442 - Do Posto Agrícola a Cáceres

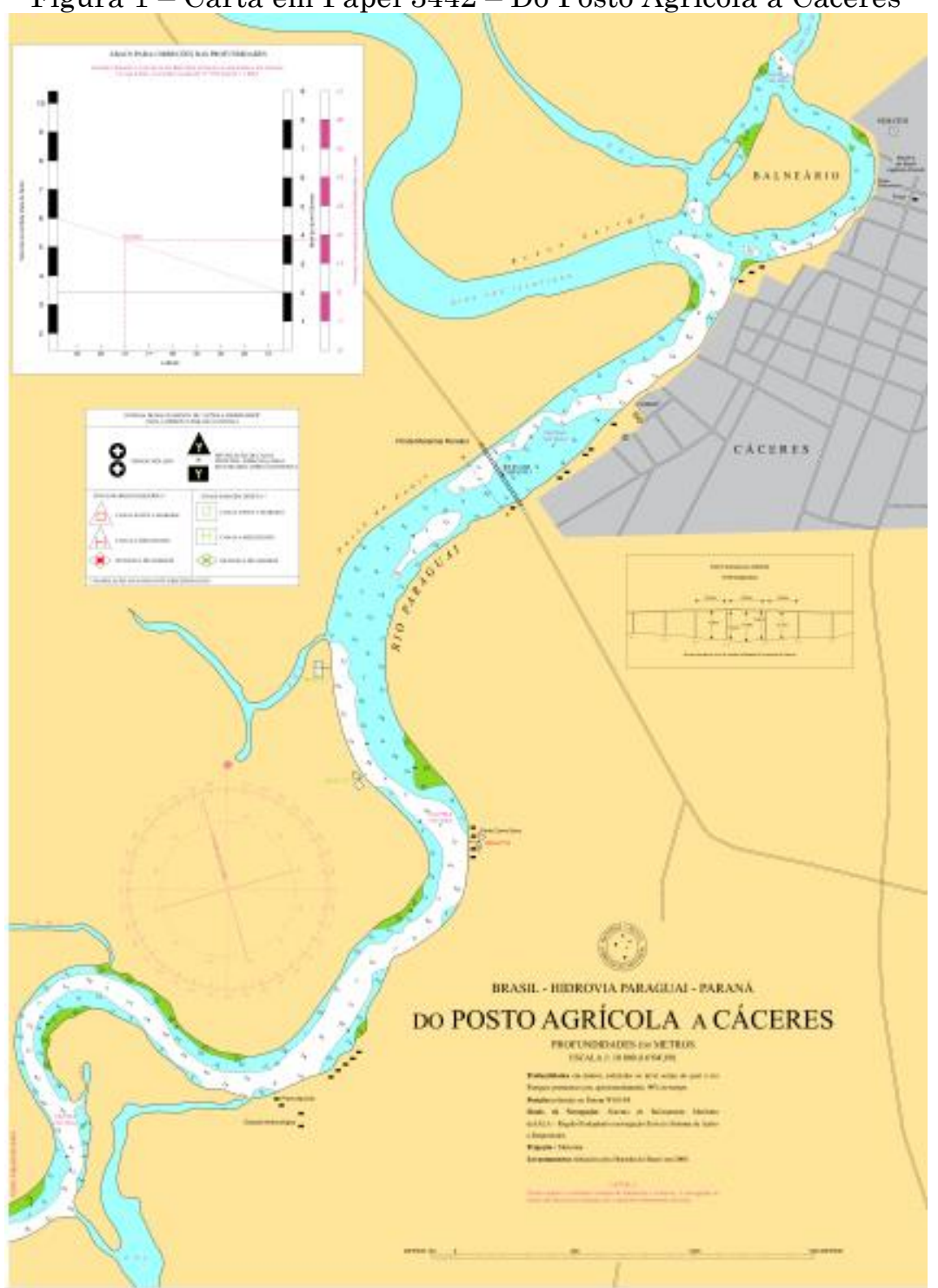

Fonte: Diretoria de Hidrografia e Navegação (2017).

\section{Levantamento Hidrográfico}

O levantamento hidrográfico foi conduzido pelo Aviso Hidroceanográfico Fluvial Caravelas, navio sob subordinação do SSN-6, e duas lanchas hidrográficas (Hotel e Índia), de 14 de janeiro a 2 de fevereiro de 2016. Foram levantados oito quilômetros do Rio Paraguai nas proximidades da cidade de Cáceres $(\mathrm{km} \mathrm{2173,8} \mathrm{a} \mathrm{km} \mathrm{2181,6)} \mathrm{no} \mathrm{estado} \mathrm{do}$ Mato Grosso.

Rev. Bras. de Cartografia, vol. 70, Edição Especial "XXVII Congresso Brasileiro de 
No levantamento conduzido pela Lancha Hotel, ilustrada na Figura 2, foi empregada técnica de levantamento com ecobatímetro monofeixe, com a utilização dos seguintes equipamentos e métodos:

a) Tipo de Posicionamento: GIPSY tempo real (RTG) com RTG C-NAV 3050, instalado na lancha hidrográfica;

b) Ecobatímetro Kongsberg Simrad EA400SP, operando em 200kHz;

c) Medida de velocidade do som: AML Oceanographic Smart $X$ (diariamente em diferentes locais dentro da área a ser levantada);

d) Software de aquisição: Hypack 2013; e

e) Software de processamento: Caris Hips \& Sips 7.1.2.

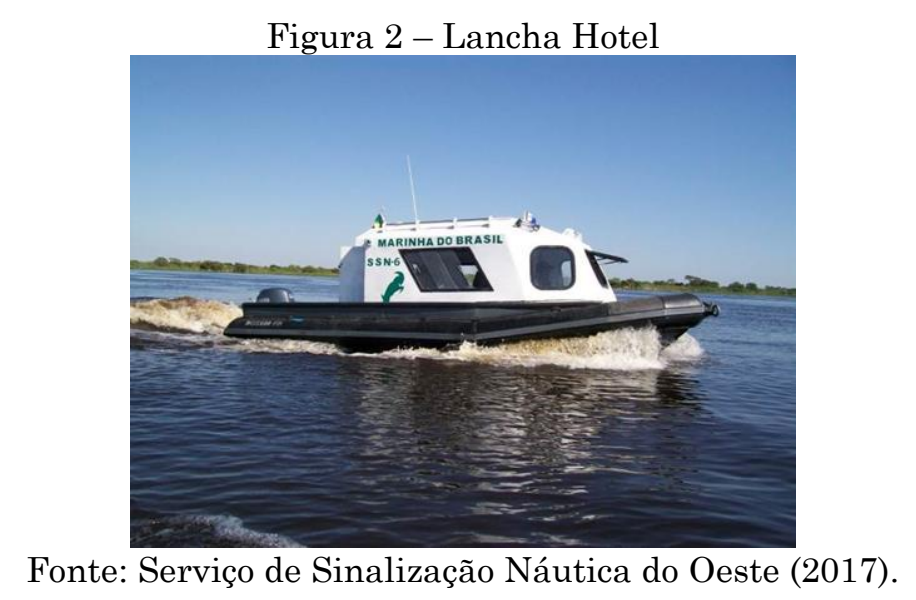

A duração do levantamento foi de 1,5 dia e aproximadamente o mesmo tempo foi necessário para processar os dados.

No levantamento conduzido pela Lancha Índia, ilustrada na Figura 3, foram empregadas técnicas de levantamento com ecobatímetro multifeixe e os seguintes equipamentos e métodos:

a) Tipo de posicionamento: Kongsberg SeaPath 320, duas antenas Novatel, unidade de referência de Movimento MRU 5, Unidade de Processamento - PU, Human Machine Interface - HMI, recebendo correções diferenciais via satélite através do RTG C-NAV 3050, instalado na lancha hidrográfica; 
b) Ecobatímetro Kongsberg EM2040 Compact Dual Head, operando em $320 \mathrm{kHz}$ - abertura angular $150^{\circ}$;

c) Medida de velocidade do som: AML Oceanographic Smart X (diariamente em diferentes locais na área a ser levantada);

d) Linhas de sondagem: longitudinalmente ao eixo do rio, espaçamento variável, dependendo da profundidade local, para garantir uma sobreposição de 100\% nas linhas adjacentes (200\% de cobertura inferior); e

e) Software de processamento: Caris Hips \& Sips 8.1.

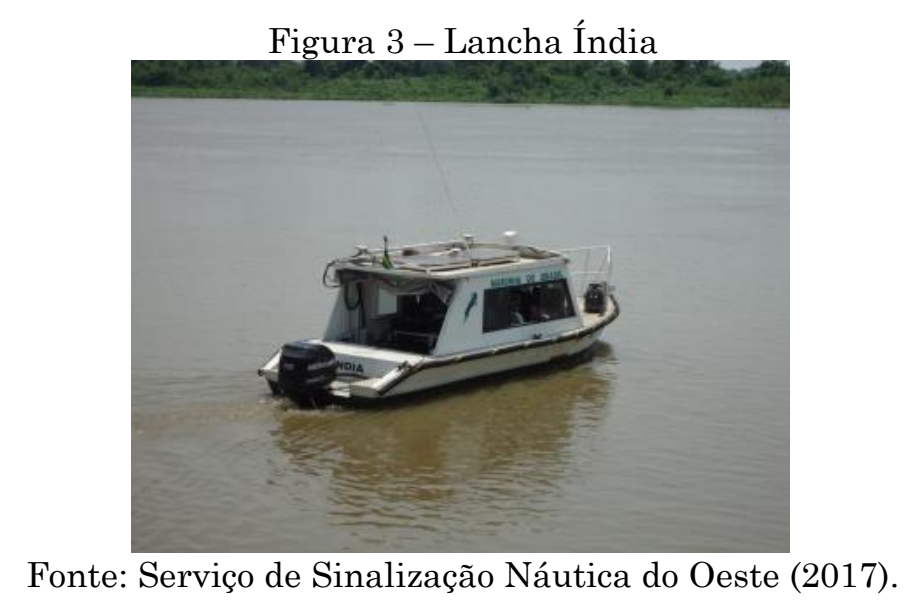

Este levantamento teve a duração de 4 dias e o tempo de processamento foi cerca de 16 dias.

A OHI não estabelece padrões de qualidade em levantamentos de rio. No entanto, o levantamento multifeixe atingiu a Ordem Especial e o levantamento monofeixe foi classificado na ordem 1B, conforme estabelecido na publicação S-44 (normas da OHI para levantamentos hidrográficos) (IHO, 2017).

Os dados de nível do rio nas réguas linimétricas, instaladas em Cáceres e em Bela Vista do Norte, foram utilizados para ajustar as sondagens. 


\section{Processo Cartográfico}

Dois arquivos foram gerados individualmente a partir de levantamentos hidrográficos com ecobatímetros monofeixe e multifeixe, de modo a subsidiar o fluxo de trabalho da produção cartográfica tradicional e o novo, respectivamente.

a) Processo Tradicional:

A primeira abordagem foi produzir uma Inland ENC a partir dos dados monofeixe, adotando o fluxo de trabalho usual já implementado no CHM para as cartas em papel do Rio Paraguai. O conteúdo da Inland ENC produzida foi baseado no conteúdo da respectiva carta 3442 , pois o processo tradicional de produção visa atender, primordialmente, à atualização das cartas em papel. Utilizando-se as ferramentas do software CARIS Base Manager, as sondagens foram automaticamente pré-selecionadas com espaçamento de 7 metros na mesma linha e mantendo o espaçamento entre linhas de 40 metros, estabelecido para o levantamento em questão para atualizar a carta $3442 \mathrm{em}$ escala 1:10.000. A Figura 5 mostra trecho da carta 3442 com as sondagens pré-selecionadas do levantamento monofeixe sobrepostas.

Figura 5 - Dados selecionados do levantamento monofeixe sobrepostos à carta náutica 3442

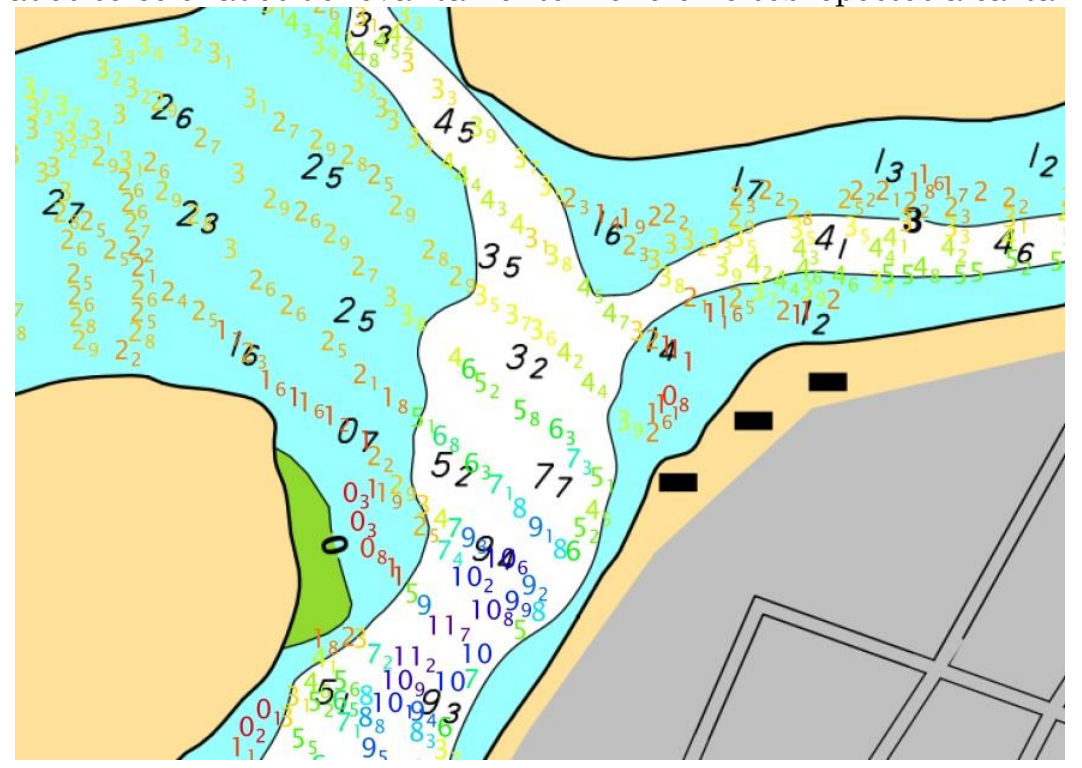

Fonte: elaborada pelos autores. 
A partir do arquivo de sondagens pré-selecionadas, foi então traçada manualmente a linha isobatimétrica de 3 metros e criadas as áreas de profundidade da carta. Em seguida, foram selecionadas as sondagens a serem incluídas na carta em papel. Ambos os processos precisam ser feitos de forma interativa para tornar os dados da carta consistentes e abrangentes. Neste contexto, é necessária uma experiência do cartógrafo ou hidrógrafo, para atingir o objetivo de indicar ao navegante onde existem áreas restritas a navegação e onde o navio pode passar com segurança. Foram necessárias 30 horas para a compilação dos dados batimétricos e criação do arquivo final tanto para a carta em papel como para a Inland ENC. A Figura 6 mostra o produto gerado adotando o processo tradicional, a partir do levantamento com ecobatímetro monofeixe.

Figura 6 - Inland ENC produzida a partir de dados monofeixe (processo tradicional), exibindo ainda o balizamento das margens do Rio Paraguai

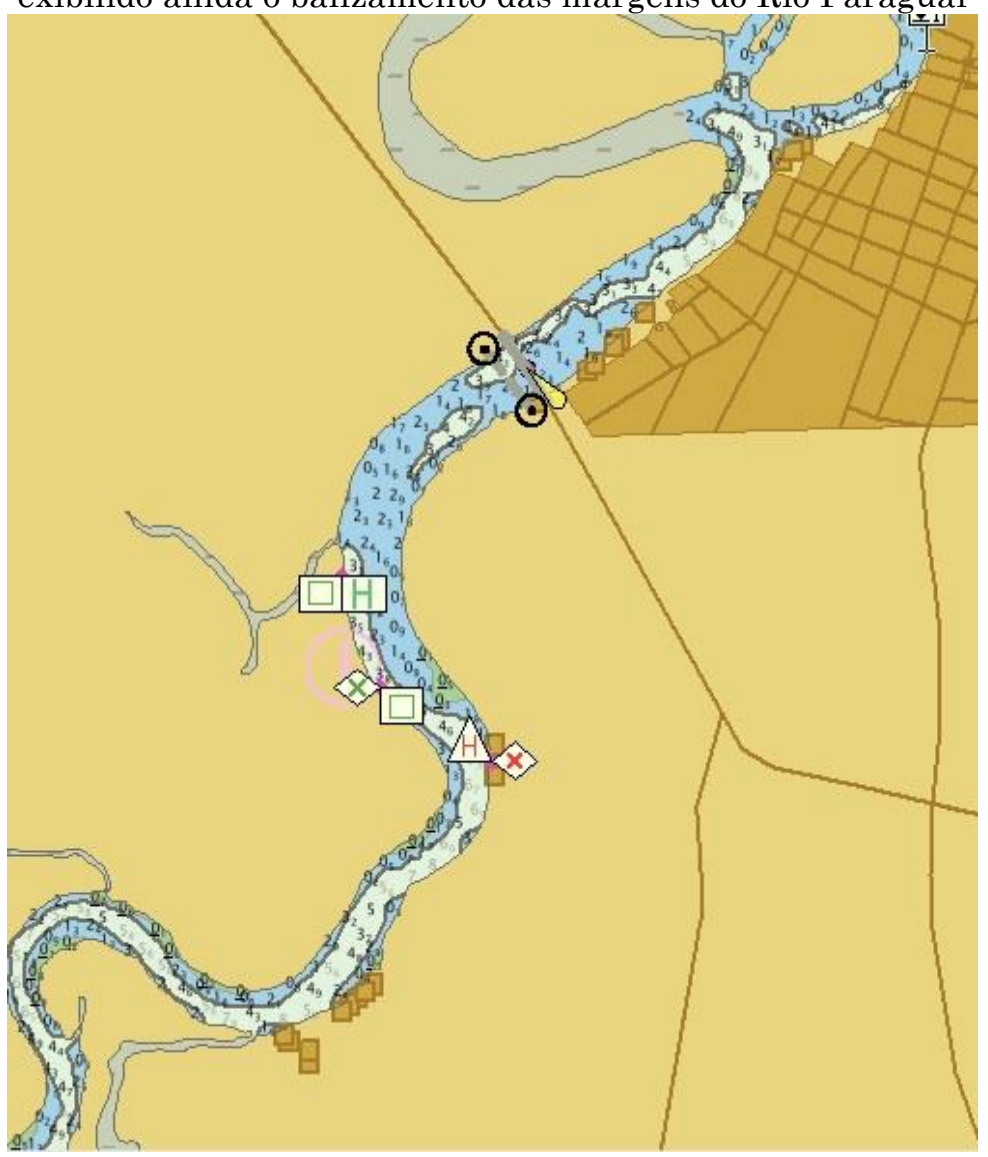

Fonte: elaborada pelos autores. 
b) Novo Processo:

Outra abordagem foi aplicada para gerar uma Inland ENC a partir de dados batimétricos de alta densidade, coletados com o ecobatímetro multifeixe. Neste processo não houve a preocupação da geração da respectiva carta em papel, que poderia ser gerada a posteriori. A maior parte das tarefas foi feita automaticamente. Com o auxílio das ferramentas do software CARIS Base Manager, as sondagens foram automaticamente pré-selecionadas com espaçamento de 14 metros. Então, uma superfície e seu derivado TIN (Triangular Irregular Network) foram gerados. A Figura 7 mostra a superfície gerada pelos dados multifeixe sobreposta à carta náutica.

Figura 7 - Imagem da superfície gerada a partir dos dados multifeixe sobre a carta náutica

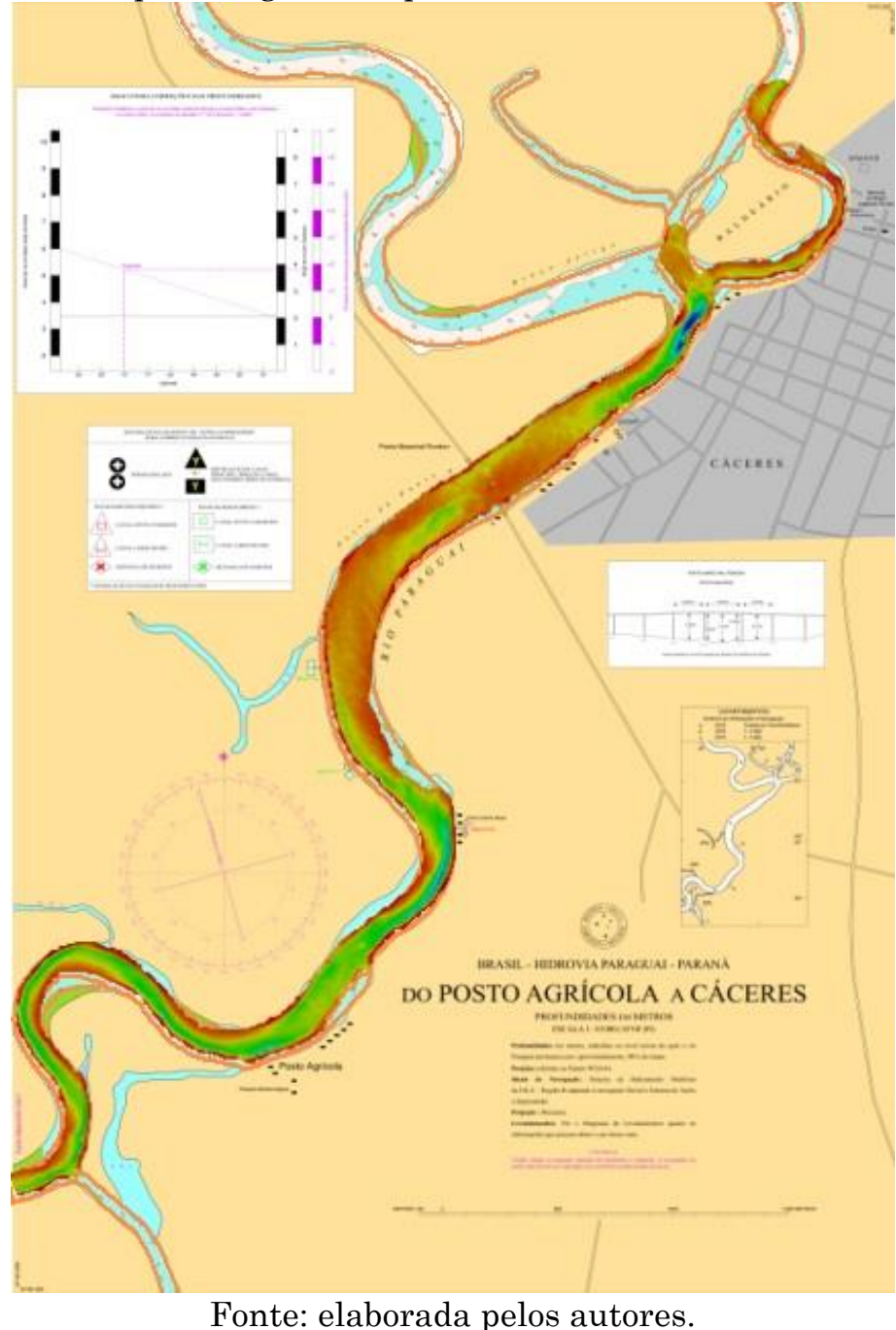


A partir do modelo de triangulação (TIN), o software permitiu que fossem criadas automaticamente as linhas isobatimétricas, a cada metro, e as áreas de profundidade da Inland ENC. Um fator de suavização 5 foi aplicado no processo. Demorou-se cerca de 40 minutos em todo o processo, incluindo uma verificação dos resultados contra a superfície batimétrica. Neste produto, não houve sondagens selecionadas porque o levantamento provê a cobertura total do fundo e as linhas isobatimétricas geradas são muito precisas, o que garante que todos os alto-fundos sejam retratados pelo software, conforme apresentado no produto final, ilustrado nas Figuras 8 e 9, onde é realçada a linha isobatimétrica de 3 metros. Entretanto, caso desejado, algumas sondagens podem ser adicionadas ao produto, inclusive por meio de seleção automática. Uma vez que a Inland ENC é um produto digital, e não há necessidade de edições para adequação dos elementos gráficos à escala de impressão da carta em papel, este processo é mais rápido do que o tradicional.

Figura 8 - Trecho norte da Inland ENC gerada a partir de dados multifeixe, com destaque na linha isobatimétrica de 3 metros (novo processo)

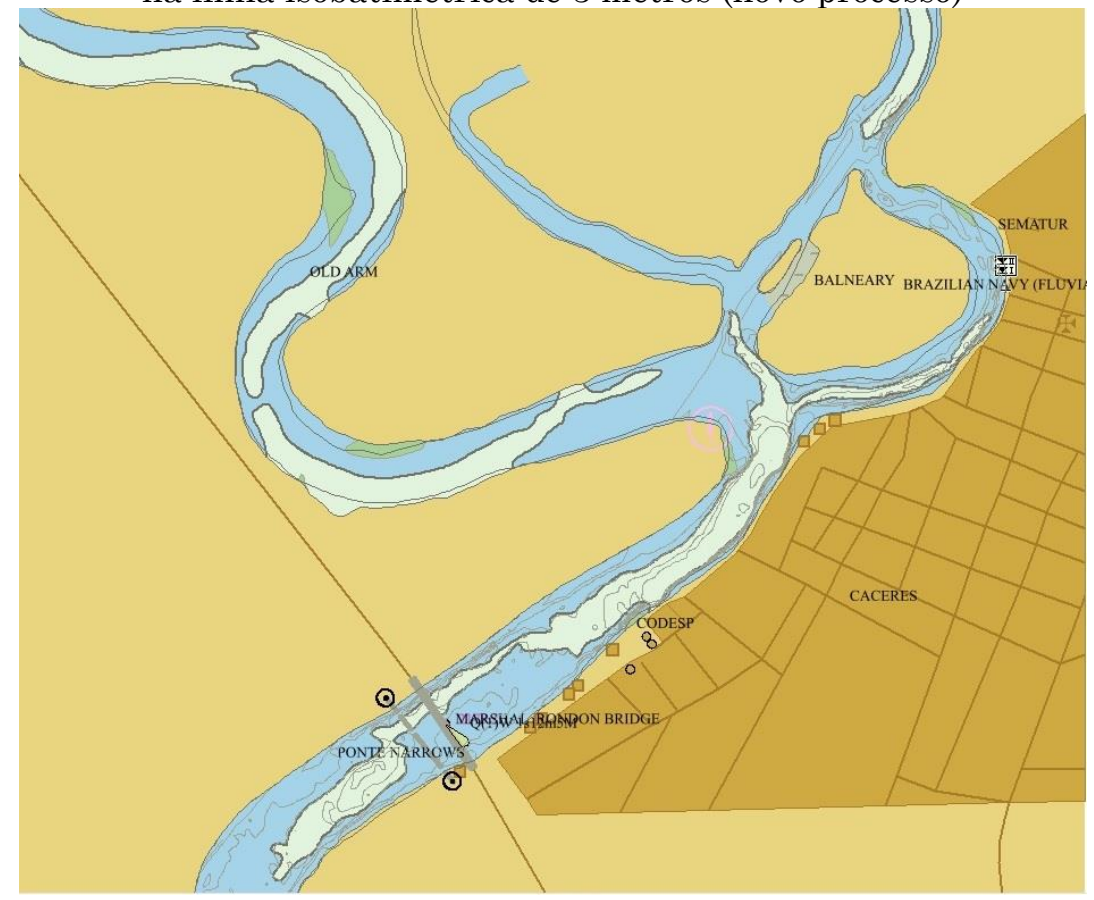

Fonte: elaborada pelos autores. 
Figura 9 - Trecho sul da Inland ENC gerada a partir de dados multifeixe, com destaque na linha isobatimétrica de 3 metros (novo processo)

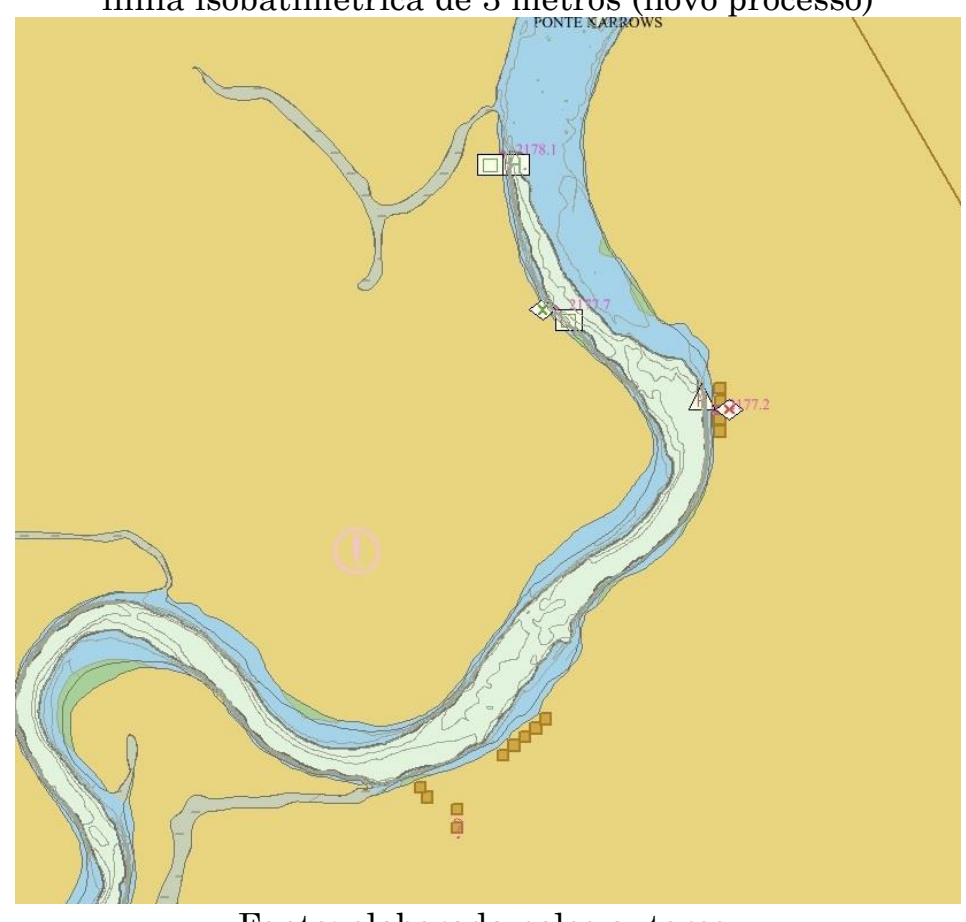

Fonte: elaborada pelos autores.

\section{Considerações Finais}

Para estruturar uma comparação entre os processos apresentados, de forma a subsidiar a especificação de um produto cartográfico eletrônico para os rios brasileiros, considerou-se útil separar a discussão em três aspectos diferentes: as diferenças quanto às características do levantamento; as diferenças quanto ao processo de construção cartográfica; e os produtos finais gerados.

Em relação às características do levantamento, algumas considerações são dignas de nota. A duração do levantamento e o tempo de processamento dos dados dependerão das características da área e de sua extensão. No caso apresentado, o tempo de processamento dos dados multifeixe é bem superior ao tempo de processamento dos dados monofeixe. Entretanto, o tempo de processamento tende a ser abreviado, em função da experiência a ser adquirida pelos hidrógrafos, além de existir a possibilidade do processamento ser iniciado na própria embarcação, ainda durante o levantamento. Portanto, 
a comparação realizada para este documento, que compreende uma área muito particular do Rio Paraguai, não pode definir uma regra abrangente.

De forma geral, os levantamentos com técnicas multifeixe exigem equipamentos mais caros e maior tempo para coletar, processar e validar os dados adquiridos. Por outro lado, observa-se que o conjunto de dados fornecido pelo levantamento multifeixe, permite uma melhor representação da realidade, em contrapartida aos dados de levantamentos monofeixe, cujos dados exigem que o modelo matemático do software estime pontos na geração das linhas isobatimétricas.

Quanto aos processos cartográficos, observou-se que a abordagem tradicional é mais demorada devido às tarefas cognitivas necessárias à seleção e generalização dos dados batimétricos com base na escala da carta em papel (MENEZES, 2013). Tradicionalmente, o objetivo da carta em papel é dar uma ideia de onde está a linha isobatimétrica de 3 metros, com margem de segurança, e representar as menores profundidades encontradas no levantamento do Rio Paraguai. Em áreas críticas para a navegação no rio, a geração das linhas isobatimétricas com margem de segurança, a partir de dados monofeixe, pode gerar documentos cartográficos com estreitamento da largura dos canais de navegação, para garantir a segurança do navegante (MIGUENS, 1996).

O processo automático de traçado das linhas isobatimétricas a cada metro, proposto para os dados coletados com ecobatímetro multifeixe, é menos demorado, mas requer também uma experiência do cartógrafo em verificar o produto resultante contra a superfície batimétrica de origem. Neste processo, as linhas isobatimétricas são bem mais precisas, e representam com grande fidelidade a conformação do fundo.

Vale ressaltar que este processo de traçado automático das linhas isobatimétricas também poderia ser aplicado aos dados coletados com ecobatímetro monofeixe, mas isto poderia dar uma interpretação enganosa dos recursos da Inland ENC ao usuário, pois as linhas, mesmo adensadas, teriam sido geradas em interpolações por modelos matemáticos. 
Conclui-se, portanto, que as Inland ENC geradas a partir de dados multifeixe são mais precisas e o processo cartográfico é mais rápido. Entretanto, a coleta e o processamento dos dados do levantamento são mais demorados. Por outro lado, os levantamentos monofeixe apresentam tempo de coleta e processamento menores, mas uma menor qualidade no produto, em virtude da menor densidade dos dados.

Em ambos os processos, os produtos gerados deverão estar atualizados e disponíveis para o navegante em tempo hábil, principalmente em áreas dinâmicas. De nada adianta ter um produto eletrônico que ofereça vantagens em relação às cartas em papel, se o mesmo não for agilmente atualizado e disponibilizado.

As características de dinamicidade do Rio Paraguai determinarão as áreas onde serão executados levantamentos multifeixe e a periodicidade dos mesmos. Os aspectos apresentados nas duas abordagens de processo cartográfico devem ser considerados para especificar as características Inland ENC do Rio Paraguai e, futuramente, de outros rios brasileiros.

\section{Agradecimentos}

Os autores agradecem à empresa Teledyne Caris pela cessão de licenças dos programas necessários à geração dos produtos aqui apresentados.

Agradecem também a colaboração do Capitão de Corveta Vitor Bravo Pimentel e do Suboficial Juarez José de Oliveira pelas informações e apoio prestados durante os testes executados e processo de produção. 


\section{Referências}

DHN, Diretoria de Hidrografia e Navegação. Site $<$ https://www.mar.mil.br/dhn/chm/box-cartas-nauticas/cartas.html>, acessado em julho de 2017.

FRIGO, A.L. e BLENINGER, T.B. A review of the Navigability Modeling for Inland Waterways, 36th IAHR World Congress, The Hague, Netherlands, 2015.

IEHG, 2013, Inland ENC Harmonization Group. Site <http://ienc.openecdis.org/>, acessado em julho de 2017.

IHO, International Hydrographic Organization. Site < http://www.iho.int/>, acessado em julho de 2017.

MANDARINO, F. Cartas Eletrônicas de Rio (Inland ENC) - Perspectivas para o Brasil, Anais Hidrográficos, LXXI, 2015. pp. 97-107

MENEZES, P. M. e FERNANDES, M. C. Roteiro de Cartografia. Rio de Janeiro. Oficina de Textos, 2013. 288p.

MIGUENS, A.P. Navegação, Ciência e a Arte, Vol I - Navegação Costeira, Estimada e em Águas Restritas. Rio de Janeiro. DHN, 1996.

SSN-6. Serviço de Sinalização Náutica do Oeste. Relatório Técnico, Ladário, 2017. 15p. 